\title{
Post-Pleistocene Changes in the Human Dentition ${ }^{1}$
}

\author{
C. LORING BRACE AND PAUL E. MAHLER \\ Museum of Anthropology, The University of Michigan, Ann Arbor, \\ Michigan 48104
}

\begin{abstract}
Published evidence indicates sharp reductions in the hominid dentition following the end of the Pleistocene. These reductions, both in size and in morphological complexity, have proceeded farthest in those areas where culture change has occurred most rapidly. The model proposed here suggests that post-Pleistocene dental reduction may be the result of the change in selective forces consequent from the invention and use of pottery and the changes in foodpreparation techniques after the end of the Pleistocene. Models for testing this hypothesis are discussed.
\end{abstract}

\begin{abstract}
“. . if it is undeniable that since the Paleolithic dental evolution has occurred in the sense that there has been a diminution in the number of teeth, a reduction in their volume, a simplification in their form and an approximation of their roots, it is no less doubtful that the occurrence of mutations at times has come to complicate and influence the general manner of that evolution." (translated from Brabant and Twiesselmann, ' $64: 55$, original in italics),
\end{abstract}

There is an assumption in many quarters that human form has remained essentially unchanged since what is called "modern" man first appears in the fossil record. In part this view is a survival from the era when the very idea of human evolution was viewed with something less than enthusiasm and when fully modern form was identified as far back in time as possible despite the exceedingly fragmentary and inconclusive evidence (Brace, '64). More recently the idea that man did in fact evolve from something that looked distinctly less than modern has gained increasing acceptance, but a vestige of the former attitude has tended to linger on in the belief that once "modern" form was achieved in the Upper Paleolithic, human evolution effectively came to a halt. Textbook accounts consistently portray Cro-Magnon man as being indistinguishable from 20 th century Europeans. To be sure, there has been a growing interest in human microevolutionary change and what has been called the processes of ongoing human evolution, but there has been relatively little concern for and almost no research devoted to understanding recent trends in human biological change where the time span is measured in thousands of years rather than known generations.

Admittedly some care is needed in the approach to such questions, given the considerable effects which environment can have on human form. Genetically similar populations can appear phenotypically quite different as the result of differences in nutrition, disease, and the effects of exercise during the growth process. Keeping this in mind, however, one should be able to choose for study some traits where change must be basically genetic and where concomitant changes in selective forces can be suggested or observed.

In a previous paper it was suggested that,

$$
\begin{aligned}
& \text { ". major modifications in structure should } \\
& \text { allow us to make inferences about the nature } \\
& \text { of alterations in the forces of selection. One } \\
& \text { of the achievements of modern anthropology } \\
& \text { has been the demonstration that the cumula- } \\
& \text { tive effect of man's traditions and activities- } \\
& \text { his culture greatly alters the nature of the } \\
& \text { operation of selective forces. Consequently, } \\
& \text { one would suspect that any pronounced } \\
& \text { alteration of selective forces, as demonstrated } \\
& \text { by a distinct structural modification, should } \\
& \text { correspond to a major change in man's } \\
& \text { cultural adaptive mechanism." (Brace, } \\
& \text { '67a:813). }
\end{aligned}
$$

Evidence for the coincidence of brain and tooth size changes with changes in cultural dimensions was then presented.

\footnotetext{
1 Earlier versions of this paper were presented before the American Association of Physical Anthropologists in the symposium Teeth as Tools, organized by Dx. Stephen Molnar, Washington, D.C., March, 1970; and at the meetings of the American Anthropological Association in San Diego, November, 1970.
} 
The focus, however, was principally directed toward events which took place during the Pleistocene itself. The concern of the present paper, in contrast, is with late Pleistocene and post-Pleistocene changes. Even though the time depth is short as evolutionary time is usually considered, nevertheless if the principles elaborated earlier (Brace, '63, '67a) have any validity, recent events should be expected to proceed in predictable fashion.

The most dramatic and easily measured changes in human form observable in the late Pleistocene are associated with the dentition and, in the section that follows, evidence will be presented which shows that changes of this nature have continued in a predictable manner after the end of the Pleistocene. It was earlier suggested that the development of specific tools for specific purposes reduced the adaptive value in the possession of a large and well-developed dental apparatus, and it was further suggested that, as a consequence, dental reduction was produced by the Probable Mutation Effect (Brace, '63).

Extending the argument, the prediction which underlies the efforts reported here suggests that the greatest amount of post-Pleistocene dental reduction should have occurred in those populations where cultural developments related to tooth use have been in effect for the longest period of time. However much the dentition may be used as an auxiliary manipulating device, its primary function has been connected with the processing of food. Throughout most of human evolution, the loss of the dentition would have severely reduced the chances of survival, simply because adequate alternate food-processing techniques did not exist. By 6,000 B.C., however, the widespread use of pottery in the Middle East (totally absent only a few hundred years earlier) completely changed the significance of the human dentition. (For a detailed treatment of a crucial archeological sequence from the pre-ceramic on, see Hole, et al., '69.) Cooking pots make possible the reduction of food items to drinkable consistency which means that the teeth are no longer really necessary for survival. Given these conditions of selection relaxation (Post, '62), one can guess that the biological consequences will be dental reduction, the mechanism being the Probable Mutation Effect (the "PME"). The operation of the PME suggests that through random mutation, the developmental processes controlled by complex genetic mechanisms will be disrupted with the final result being an incomplete or simplified structure (Brace, '63). This suggests that the most likely results of the most likely mutationsthe probable mutation effect-will be structural reduction. Obviously such an "effect" can only be of importance where the forces of selection are relaxed or suspended.

The validity of the PME as a changeproducing mechanism has been challenged by some, and we do not intend to use this occasion to produce a detailed defense. In passing, however, it should be mentioned that, if the universal pleiotropy critique of Wright ('64) and Holloway (66) were valid, then the increase in frequency of a beneficial trait under the impetus of natural selection would be just as impossible as the decrease following selection relaxation. The objection has been offered that a trait is not free to vary when selection for it is reduced because the adaptive value of the other traits controlled by the same genetic background probably will not also be reduced. In reply, it should be noted that the development of a particular advantageous trait would be similarly inhibited because, in like fashion, it is unlikely that the other traits influenced by the controlling gene would also be advantageous. The assumption of universal pleiotropy, then, is just as great a stumbling block to maintaining an orthodox view of evolution by means of natural selection as it is to reduction following selection relaxation as suggested by the PME. Recent work in molecular biology has demonstrated that mutations can and do occur without being subjected to the forces of selection (King and Jukes, '69), and that frequently they can have such specific effects that pleiotropy is not involved (Auerbach, '67). This bolsters the logic initially used to propose the PME.

Of course it is always possible that particular reductions are in fact advantageous and are the direct result of 
selection pressure. But if, after prolonged and careful investigation, an observed trend toward reduction cannot be associated with any accruing benefits, it would be an abdication of scientific responsibility to declare that natural selection must be operating even if the mechanics are undiscoverable. Reductions have been documented in such human traits as vision, nasal septum form, and tear duct size where conditions of selection relaxation have been noted (Post, '62, '65, '69a,b), and it is possible to suggest that the mechanism has been the PME.

In some instances the attempt to invoke "ordinary natural selection" is supported by somewhat unconvincing explanations as for instance the claim that dental arch size "in the later stages of man's evolution" is reduced because the lessened angular momentum of the craniofacial mass increases possible headswivelling speed (Brues, '66). We suspect that the small but consistent dental reduction which distinguishes modern Europeans from their Mesolithic ancestors cannot be accounted for by suggesting that it represents the survival value of being able to look back over one's shoulder with significantly greater speed.

Post-Pleistocene reduction in the human dentition has been recognized by a few scholars, notably by the late Sir Arthur Keith ('20, '23, '24, '28), with impressive documentation by Brabant and Twiesselmann ('64), by D. A. Lunt (69), and by D. L. Greene (70). The following section presents quantitative evidence which bolsters the picture of postPleistocene dental reduction and adds support to suggestions concerning why these changes have occurred where and when they did. It is obvious that the evidence that has been collected here is far from conclusive. Normally such a poorly supported case would not justify presentation, but in this instance we feel that presentation of the model itself will allow others who have access to more data to perform the tests which are indicated. One thing that has become evident as a result of these efforts is the extremely limited amount of information available in the published literature. If this attempt has no other result, at least we hope that we shall have stimulated work on the collection and publication of quantitative information on the dentitions of living and prehistoric human populations.

\section{THE EVIDENCE}

Since the present concern is with late and post-Pleistocene dental reductions, the condition which preceded the reductions should be initially specified. As a point of departure, the procedure previously discussed (Brace, '67a) of using the Neanderthal dentition as a model has been followed. There may well have been local differences, but the remarkable metric similarity between the Krapina Neanderthal teeth and those of the Homo erectus ("Sinanthropus") population of Choukoutien (Brace, '67a: fig. 2) suggests that the forces of selection had remained approximately the same for about half a milliion years, at least as far as the teeth were concerned. The $\mathrm{Ne}$ anderthal dentition then should serve as a better general model for the condition from which all modern forms evolved than blind chance alone would have predicted.

The Krapina collection, measured by the senior author, includes the greatest number of known Neanderthal teeth, and, although all the other Neanderthal teeth for which measurements are available (Patte, '62) have been added to the sample on which our graphs are based, the Krapina teeth obviously are numerically the most important. The additions in fact make little change in the mean figures.

Because a good portion of our information concerning the Neanderthal dentition comes from loose teeth, there is no way to identify sex. Even among more recent archeological collections where skeletons are more likely to be complete, the problem of identifying sex is difficult. Consequently we have followed general practice and made no attempt to separate the data by sex. The measurementsmesial-distal (MD) and buccal-lingual (BL) - whether taken by ourselves or by those whose data we use, were done according to the convention described by Goose ('63). Some of the Neanderthal teeth and most of those in the more recent populations remain implanted in 
mandibles and maxillae. To facilitate their measurement, the tips of a standard Boley gauge were ground fine enough so that they could slip between adjacent teeth, allowing a proper MD measurement to be taken from contact facet to contact facet. Data were collected only on permanent teeth which had not been worn to the point where one would suspect serious alteration in the measurements. Our experience corroborates Goose's observation that the accuracy of independently repeated measurements is not greater than one-tenth of a millimeter. Consequently we recorded our individual tooth measurements (MD and $\mathrm{BL}$ ) to a single decimal place.

As in the earlier paper (Brace, '67a), these graphs present a kind of profile of cross-sectional areas, tooth by tooth, for visual ease of comparison. Admittedly the product of the MD and BL crown dimensions is not an exact representation of cross-sectional area since crown form is not precisely parallel-sided, but it is the best approximation that can be quickly produced, and since it is constructed from measurements most frequently recorded in the literature, it is the most convenient basis for comparing dental wear potential in various populations. As conditions of selection change, variation in crosssectional area should be a good indicator of the biological response.

The data on which our graphs (figs. 1-12) are based are presented (in square millimeters) in tables 1 and 2. Where our published sources reported MD and BL means instead of individual measurements, we multiplied these means (mean $\mathrm{MD} \times$ mean $\mathrm{BL}$ ) to provide our approximation of cross-sectional area. In these cases, no estimate of variance was possible. Where we had access to data on individual teeth, we could calculate crosssectional area for each, plus means and standard deviations for the populations. The measurements included are uncorrected for body size since, for the time being, we are accepting the evidence which suggests that the relationship between tooth size and body size in populations of the genus Homo is "effectively nil" (Garn and Lewis, '58:878).

The between-population differences in cross-sectional area visible in these graphs are not large, and only a few are "significant" by simple statistical tests such as Student's $t$ (and this cannot even be done for most of the Old World examples because variance figures are lacking). The comparisons can be checked by using $x^{2}$ tests, the results appearing in table 3 . Evidently there are significant differences between the largest (Neanderthal) dentition and most of the others. The smallest (12-16th century Europeans) also differs significantly from most of the others. More interesting than the significance of the difference of the most widely separated populations, however, is the consistency of the direction of the change through time in a given geographical area.

Figure 1 (maxilla) and figure 2 (mandible) show how size is reduced for each tooth between the Neanderthals and the European Upper Paleolithic. Proceeding in time, figure 3 and figure 4 show that there was a further drop in tooth size among the Mesolithic populations of post-Pleistocene Europe and that, during the last 5,000 years, this has continued in the same direction. The Upper Paleolithic figures were principally derived from the Predmost material (Mateigka, '34) to which other available measurements were added." While Predmost is in East-Central Europe rather than Western Europe, it provides the only relatively complete data on Upper Paleolithic teeth. From the scattered comparative evidence available, the teeth appear to be representative of dental size throughout Europe at that time. The Mesolithic data were taken from material excavated at Rouffignac in southwestern France (from Sahly et al., '62), and the "modern European" information came from skeletal material in a twelfth to sixteenth century graveyard on the Belgian-French border (from Twiesselmann and Brabant, '60).

While there is little or no significance by $\chi^{2}$ test in the difference between each group and its temporal successor, the

a The additional measurements were taken from a wide variety of sources. Rather than cite each one, we refer the reader to the list in Wolpoff ('69, and in press). To be absolutely sure of the accuracy of our figures, however, we used only those that we could check in numerical form in the cited original sources omitting those that were taken from scaled photographs. 


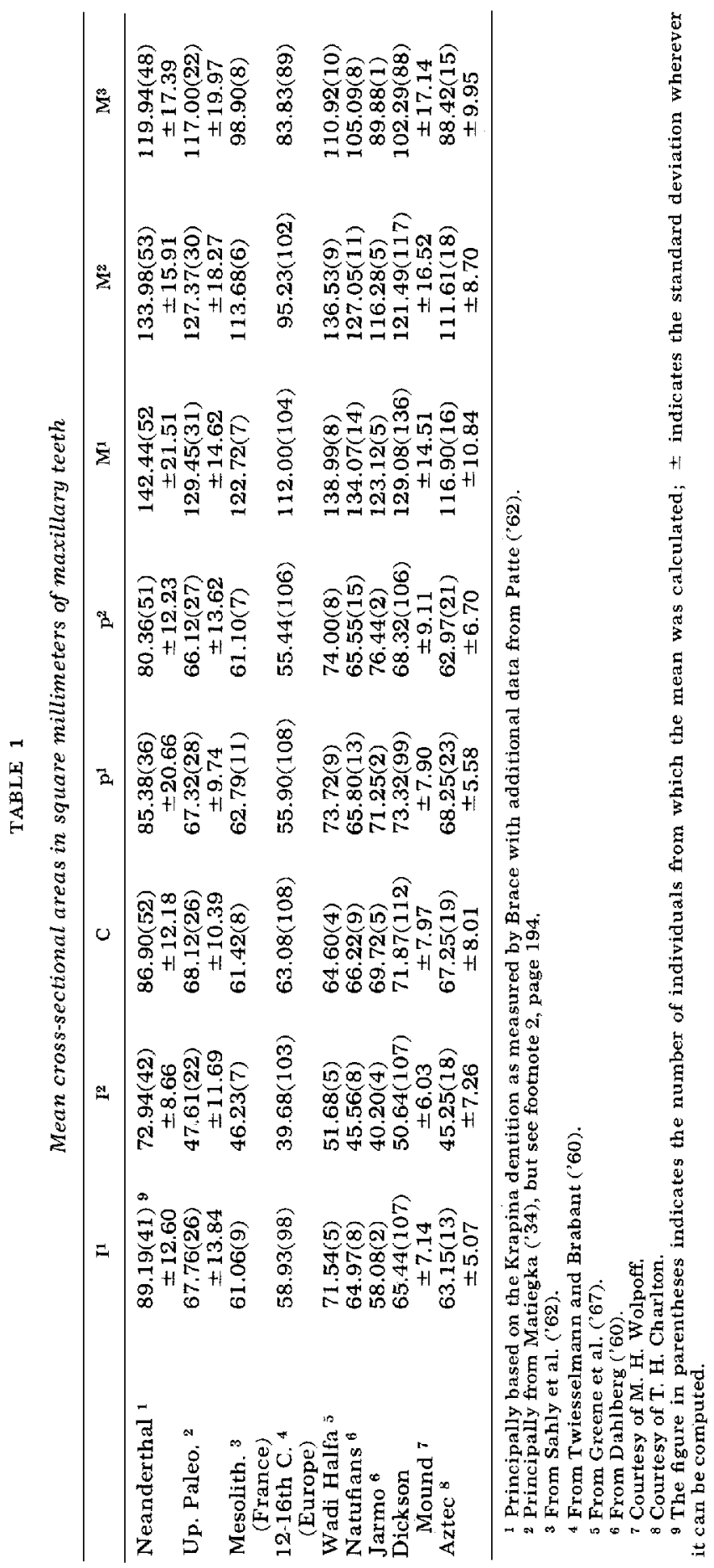



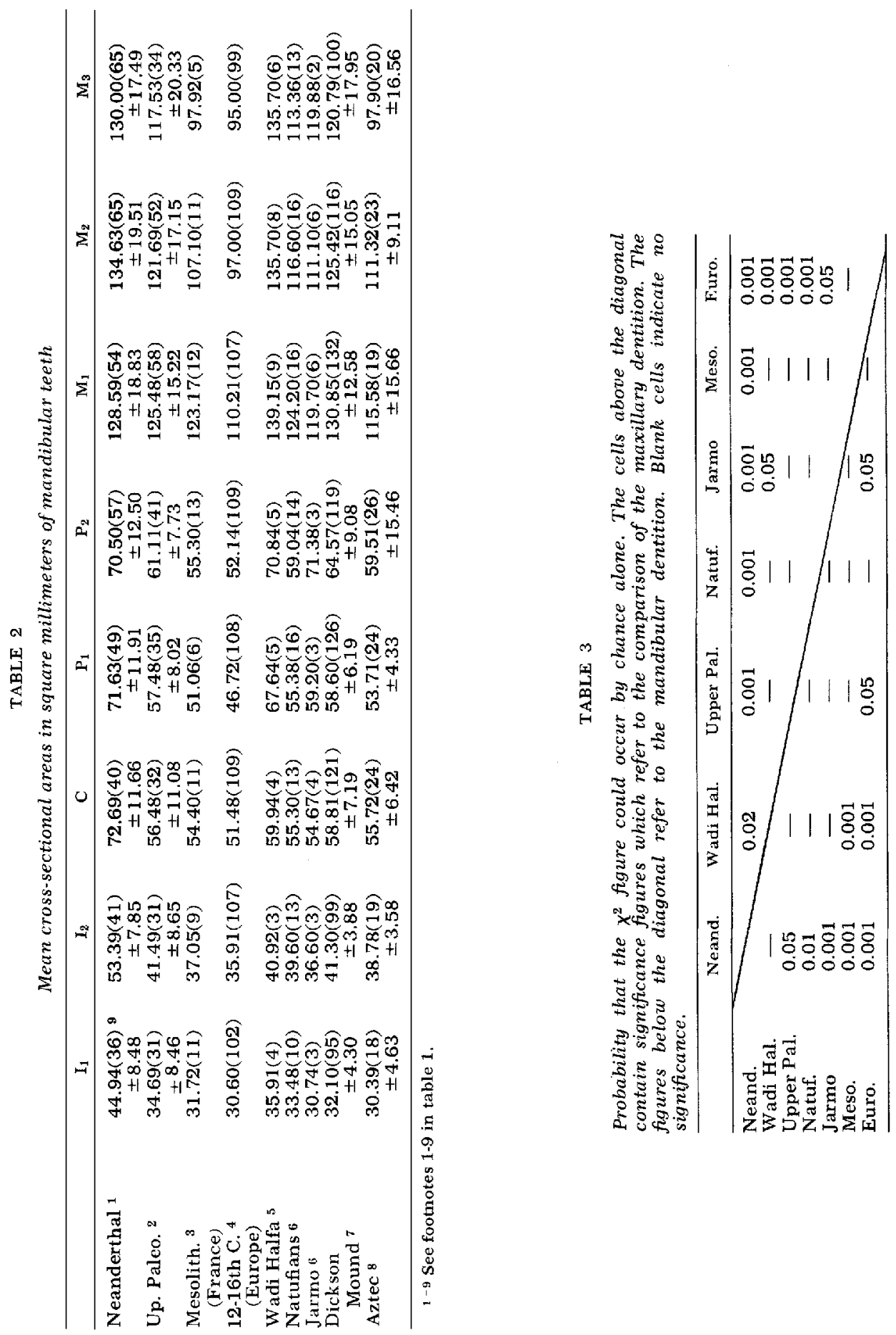


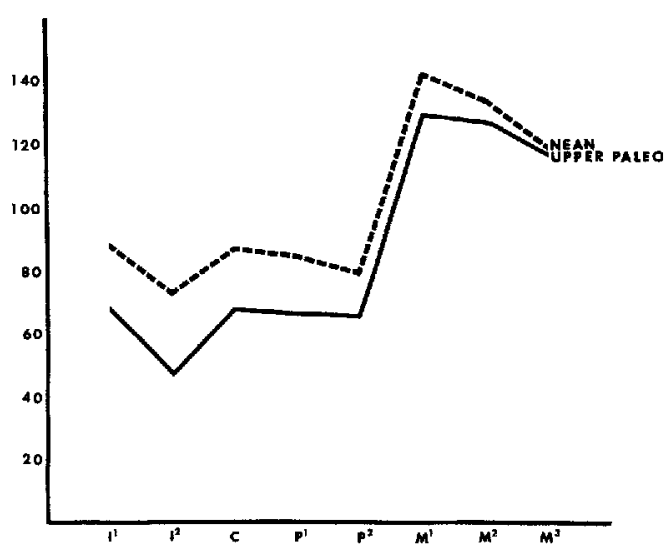

Fig. 1 Cross-sectional areas in square millimeters for the maxillary teeth of Neanderthals, represented principally by Krapina, but with everything else available added (from Patte, '62) compared with the Upper Paleolithic, represented principally by Predmost, but, again, with everything else available added (see footnote 2, page 194).

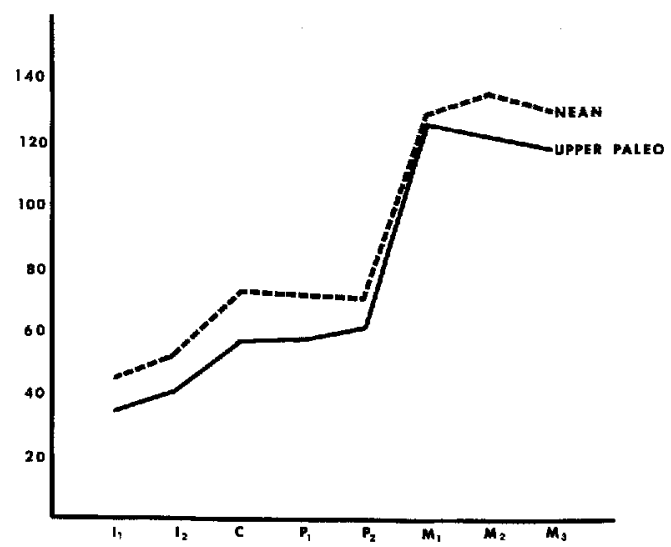

Fig. 2 Cross-sectional areas in square millimeters for the-mandibular teeth of the Neanderthals compared with the Upper Paleolithic.

existence of non-random changes is shown by the use of the Wilcoxon matched-pairs signed-ranks test. The probabilities that the differences are due to chance alone are presented in table 4. Actually these probability figures (as is true also in table 5) assume that twotailed test logic is being pursued; that is the mere existence of difference is being tested, whether consistently larger or consistently smaller. Since we have predicted that change should occur in a given direction-reduction-through

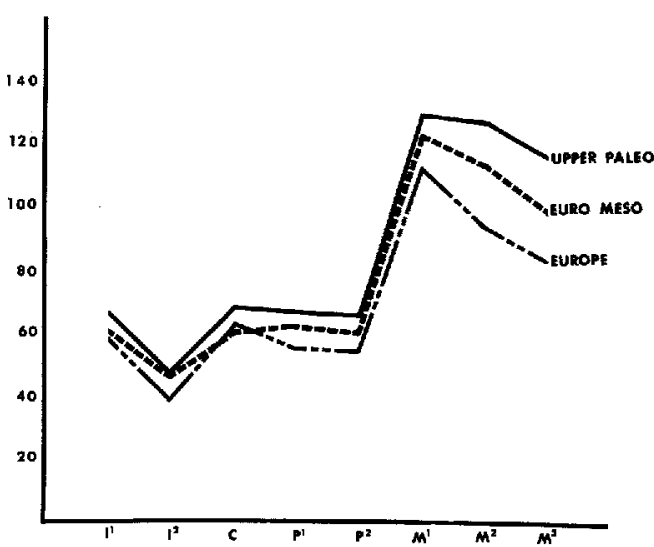

Fig. 3 Cross-sectional areas in square millimeters for the maxillary teeth of the European Upper Paleolithic, Western European Mesolithic (Rouffignac), and "modern" Europeans (12th to 16th century French).

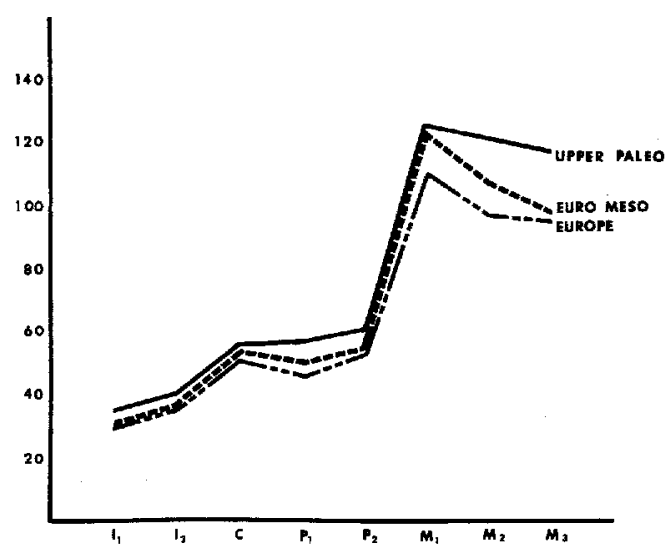

Fig. 4 Cross-sectional areas in square millimeters for the mandibular teeth of European Up per Paleolithic, Mesolithic, and modern populations.

time, we could justify using the significance levels for a one-tailed test. This would convert 0.02 to 0.01 and 0.01 to 0.005 giving even stronger support to our hypothesis.

There are no data on skeletal or dental form from the Middle Eastern Upper Paleolithic; the nearest thing that could be used as a substitute was the information from the Mesolithic population from Wadi Halfa in the Sudan (Greene et al., '67). Geographically this falls right at the edge of, or slightly outside, (Wendorf et al., '70) what has been called the "Mousterian Culture Area" (Brace '67b; and 
TABLE 4

Probability that differences are due to change alone based on the Wilcoxon matched-pairs signed-ranks test. The cells above the diagonal contain significance figures which refer to the comparison of the maxillary dentition. The figures below the diagonal refer to the mandibular dentition.

\begin{tabular}{|c|c|c|c|c|}
\hline & Neand. & Upper Pal. & Meso. & Euro. \\
\hline Neand. & & 0.01 & 0.01 & 0.01 \\
\hline Upper Pal. & 0.01 & & 0.01 & 0.01 \\
\hline Meso. & 0.01 & 0.01 & & 0.01 \\
\hline Euro. & 0.01 & 0.01 & 0.02 & \\
\hline
\end{tabular}

TABLE 5

Wilcoxon matched-pairs signed-ranks test probability figures. Cells above the diagonal refer to maxillary tooth-size comparisons; below to mandibular. Blank cells indicate no significance

\begin{tabular}{lcccc}
\hline & Neand. & Wadi Hal. & Natuf. & Jarmo \\
\hline Neand. & & 0.02 & 0.01 & 0.01 \\
Wadi Hal. & $\overline{0}$ & 0.01 & 0.02 & 0.01 \\
Natuf. & 0.01 & 0.02 & - & - \\
Jarmo & 0.01 & & & \\
\hline
\end{tabular}

see discussion in Bordes, '68:126). Since the Wadi Halfa region lacked the relatively long history of technological elaboration which grew from the Mousterian and flowered in the Upper Paleolithic in the core of this area, one would expect that the selective forces operating on the dentition of the Sudanese Mesolithic population would be roughly equivalent to those in effect further north and northwest during the Upper Paleolithic. In fact, the tooth measurements of the Wadi Halfa population (6,000 to 9,000 B.C.) are of about the same size as those of the European Upper Paleolithic as is shown in figures 5 and 6 . The differences are not significant by $\chi^{2}$ test (see table 3 ), although the larger average size of the Wadi Halfa posterior dentition accounts for the fact that the mandibular teeth are not significantly different from the Neanderthal dentition either by $x^{2}$ or by the Wilcoxon matched-pairs signed-ranks test (see tables 3, 5).

Plotting the Middle Eastern sequence in analogous fashion to the Western European sequence of figures 3 and 4 , one can see a representation of postPleistocene change in figures 7 and 8 . Note that the teeth from the Neolithic population of Jarmo (Iraq) average out to be only slightly smaller than the Mesolithic Natufian population from Palestine (Dahlberg, '60) and that the difference is not statistically significant (see tables 3 , 5). Pottery was not present at the beginning of the phase represented at Jarmo, although it did appear during that phase (see Braidwood and Howe, '62), and the selective pressures on the dentition must have been nearly the same as for a Mesolithic population. Note in figures 9 and 10 that the Jarmo measurements fit into the Western European sequence in very much the same way as did the French Mesolithic population shown in figure 3 and 4 . The Mesolithic and Jarmo dentitions do not differ significantly by either of the statistical tests used.

Predicting from this evidence, one might expect that still more recent populations should have yet smaller teeth, but here we run into an embarrassing lack of data and we cannot use the graphic form of our previous examples. Incomplete evidence (lacking incisors, canines and third molars) from modern descendants of these earlier Middle Eastern populations does indeed support the predictions (Rosenzweig and Zilberman, '67). This same problem-lack of sufficient published data-prevents our doing much more than suggesting one of the more interesting predictions that comes from this model. It is mentioned here in hopes that others who have access to data can put it to the test. 


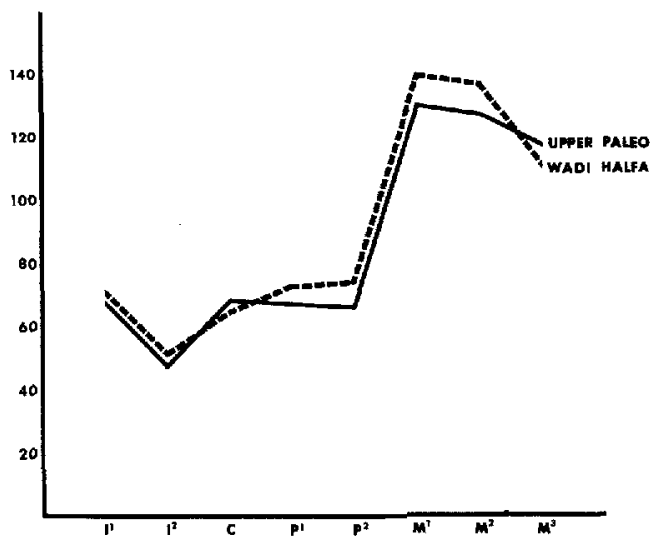

Fig, 5 Cross-sectional arcas in square millimeters for the maxillary teeth of the Mesolithic population from Wadi Halfa (Sudan) compared with those from the European Upper Paleolithic.

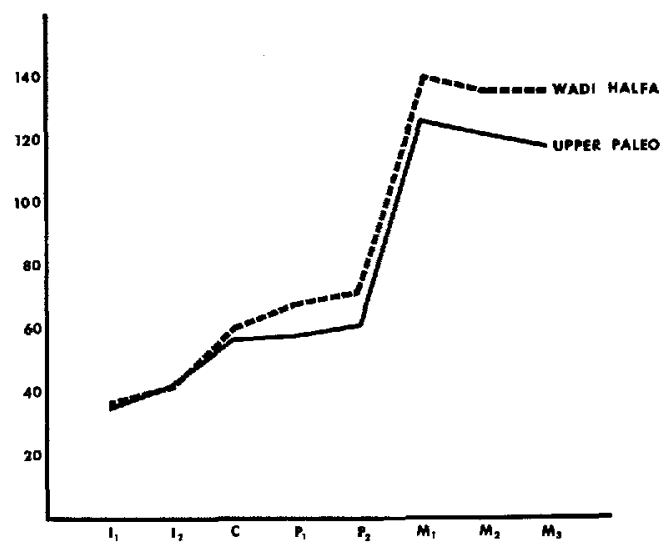

Fig. 6 Cross-sectional areas in square millimeters for the mandibular teeth of Wadi Halfa compared with the European Upper Paleolithic.

We have suggested that dental reduction was accelerated in the postPleistocene as a result of the major changes which occurred in subsistence technology, particularly food preparation techniques. These, however, did not occur everywhere at the same time. In the area that has been the principal concern in this paper, the food-producing revolution occurred first in the Middle East, spreading west and north rapidly at first and, at the end, relatively slowly (Waterbolk, '68:1101). The biological impact of this change in the nature of selective forces has been in operation at least twice as long for the populations of the Middle East and adjacent areas as it has at the northwestern margin. Consequently, the existence of a tooth-size cline in modern Europe would be predicted, starting with minimum measurements in the Middle East and reaching a maximum in Scandinavia and the northwestern edges of the British Isles. What incomplete evidence there is (compare Dockrell, '56, and Lysell, '58a,b, for the northern and western extremes with Rosenzweig and Zilberman, ' 67 , for modern Middle Eastern figures) does not contradict this suggestion; personal observation of face and jaw size reinforces it, although we are

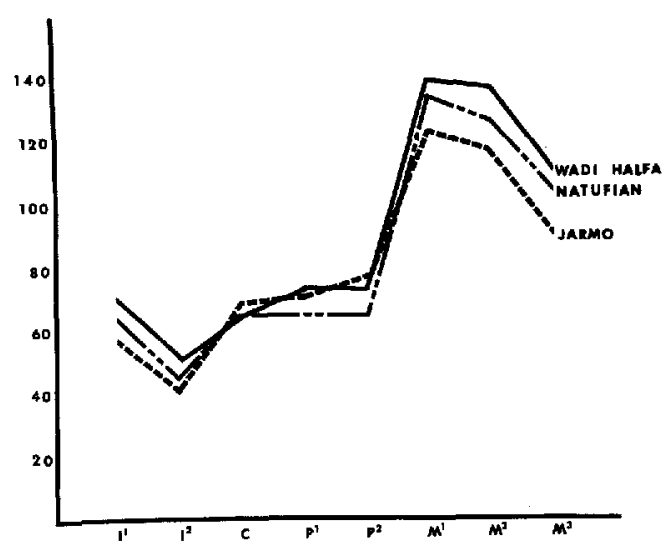

Fig. 7 Cross-sectional areas in square millimeters for the maxillary teeth of the late Pleistocene and post-Pleistocene sequence of the Middle East, using Wadi Halfa as the equivalent to the European Upper Paleolithic, the Natufians of Palestine for the Mesolithic, and Jarmo (Iraq) as Neolithic.

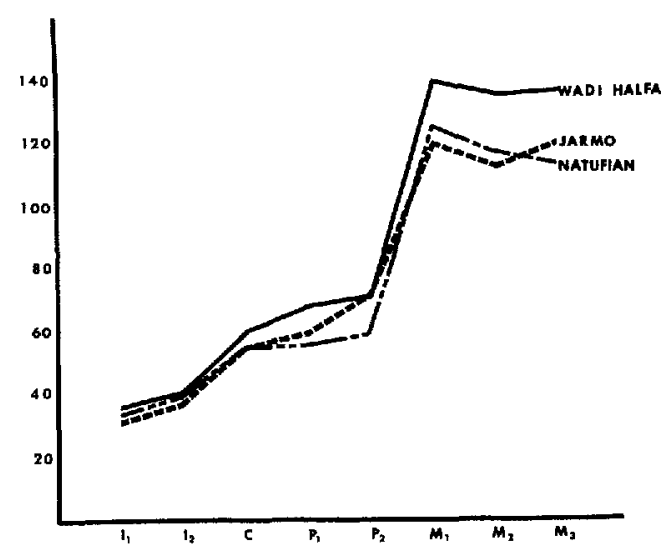

Fig. 8 Cross-sectional areas in square millimeters for the mandibular teeth of the late Pleistocene and post-Pleistocene sequence of the Middle East. 


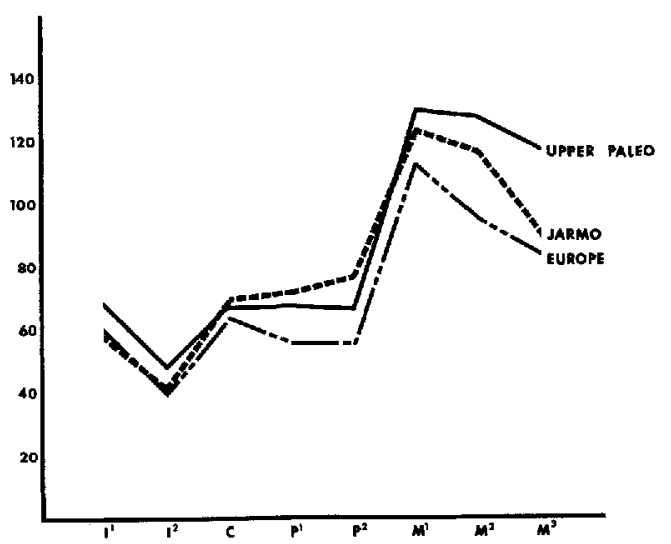

Fig. 9 Cross-sectional areas in square millimeters for the maxillary teeth of the late Pleistocene and post-Pleistocene of Western Europe compared with the Jarmo Neolithic population from the Middle East.

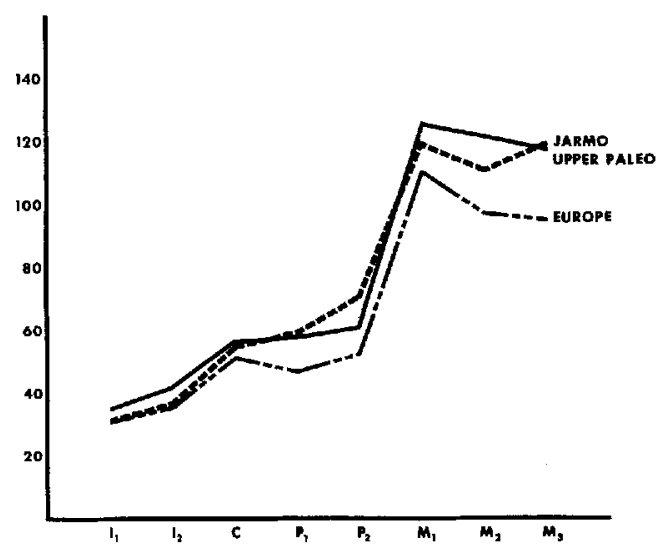

Fig. 10 Cross-sectional areas in square millimeters for the mandibular teeth of the late Pleistocene and post-Pleistocene of Western Europe compared with Jarmo.

again thwarted by an embarrassing lack of basic data.

If this interpretation has any merits, it should work in other parts of the world as well. It could be applied for East and Southeast Asia, Africa, and India, but again, data simply have not been collected. Even though time depth is quite short, this prediction should also be testable on New World skeletal material, and here we have just enough information to suggest that it does indeed work. Figures 11 and 12 show the tooth size profiles of the inhabitants of San Juan Teotihuacan at the point of contact with the Spanish (but before intermarriage) com- pared with the Middle Mississippian people of Dickson Mound, Illinois. Since the food-producing revolution and the use of pottery have been factors in the life of the populations of the Valley of Mexico for a longer period of time than has been the case further north, one would expect the maximum amount of dental reduction among the aboriginal inhabitants of the New World to have occurred there. One would also expect the least amount of reduction to be found in those peoples who were north of the boundary of New World agriculture. Unfortunately the specimens of these latter available to us displayed such heavy wear, particularly

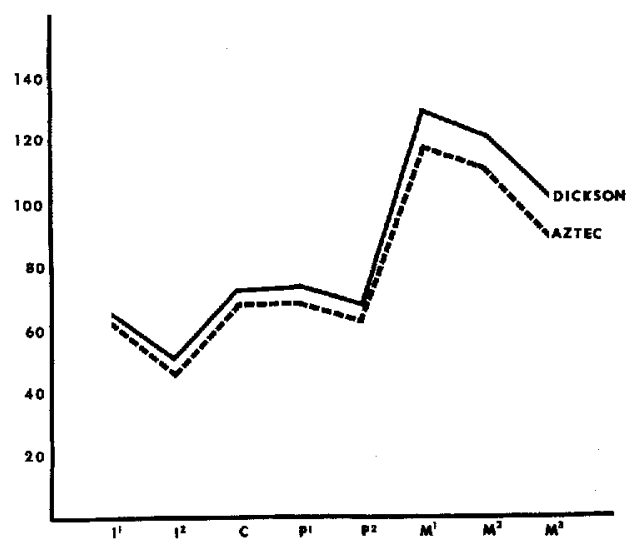

Fig. 11 Cross-sectional areas in square millimeters for the maxillary teeth of a late Aztec population at San Juan Teotihuacan, Mexico, compared with the Middle Mississippian Indians of Dickson Mound, Illinois.

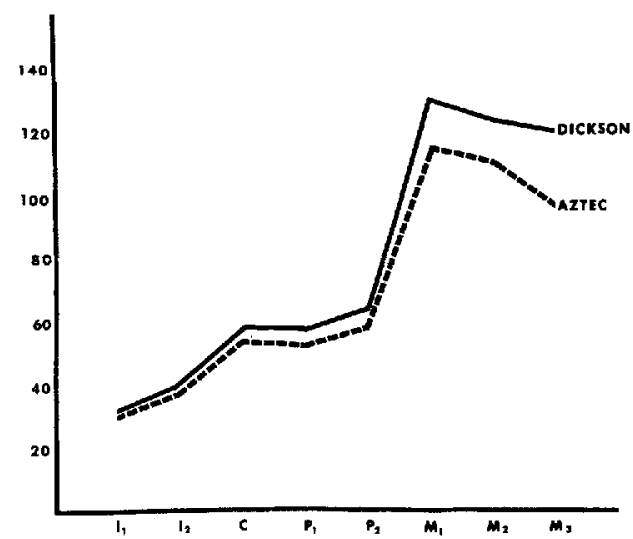

Fig. 12 Cross-sectional areas in square millimeters for the mandibular teeth of Aztec com pared with Middle Mississippian Indians from Illinois. 
on the incisors, that we could not use them for comparative purposes, although the few relatively less worn teeth do tend to confirm our expectations. Instead, we have used information from the northernmost population available. The contrast between San Juan Teotihuacan and Dickson Mound is not dramatic and not significant by $\chi^{2}$, but it is consistent and in the direction of our prediction; and it is highly significant by the Wilcoxon matched-pairs signed-ranks test (0.005).

From a quick visual inspection one retains the impression that morphological reduction has also, predictably, gone to a greater extent in the Aztec teeth. Specifically, reductions in hypocone (upper molars), hypoconulid (lower molars), shovelling (incisors), missing third molars and lateral incisor reduction all appear more pronounced than in the teeth of Middle Missippian Indians. This, however, is a superficial impression and should be checked by conventional comparative methods.

\section{NON-GENETIC CHANGES}

Crown morphology and actual dental dimensions are clearly under direct genetic control. Changes in these traits represent genuine biological evolution, but there are other changes in the dentition and its supporting structure that are non-genetic. Shape of the palate, cheekbone development, gonial angle size, and the form of occlusion can be greatly altered by different environmental stresses that impinge on the dentition during the growth process (Hunt, '60). One of the striking changes that has recently taken place in the human dentition appears to be of this nature and deserves some comment here. This is the appearance of the overbite.

Some years ago, the somewhat simplistic suggestion was advanced that this was a functional mechanism which was developed to promote a distal wedging action (Brace, '62). The overbite did not appear with the food-producing revolution, however, and did not come to characterize the European occlusion until after the Middle Ages (see comments by Keith, '20:85 and '24:136). The parallel between the adoption of the table fork (including the gastronomic habits implied) and the appearance of the overbite is too striking to be coincidental. The diffusion of the fork from Italy to northwest Europe in the 17th century (Montagné, '61; Deetz, '69) drastically altered "civilized" eating habits. Henceforth food items were held down on the plate for cutting instead of being clamped between the incisors to be torn or cut into chewable size.

As always when one believes he has thought of something original, someone else inevitably said it before. So it is in this case. The statement, in a report on the "mound-builders" who fascinated the literate a century ago, is explicit enough to warrant quoting.

"This form of the teeth (edge-edge bite, tlat wear) is not peculiar to the mound-builders but is characteristic of savage races generally. The disuse of the front teeth for the purpose of severing mouthfuls of food from the mass, consequent upon the use of the knife and fork, materially modified the process of mastication and the form of the teeth." (Henderson, '82:711).

Actually wear is not necessary to produce an edge-to-edge bite since this form of occlusion can be observed in individuals where no wear is present. The simple habit of using the incisors to hold food while it is being cut apparently prevents the over-eruption of both maxillary and mandibular incisors which creates the overbite. The issue of the overbite is raised, not because this suggestion is necessarily correct, but because it, like many other questions that have been with biological anthropology for a long time, could easily be solved with a little problem-oriented research.

\section{CONCLUSION}

The evident conclusion which emerges from this survey is that the data which could be used to test the hypotheses which have been tendered here have yet to be collected. Attempts to interpret the significance of human variation by noting the coincidence between clines in putative selective forces and accompanying variation in inherited (although undoubtedly polygenic) traits have been regarded with "despair" as examples of 
"soft thinking" and dismissed with the words, "The viewpoint is modern, but the methodology so very old" (Harrison, '65:295). One could reply that the speculative nature of papers such as this is due to the fact that so few have actually done the work of acquiring the necessary data. If teeth are measured, incisors or perhaps third molars are not reported. More frequently, only mesial-distal measurements are taken in spite of the fact that, particularly in populations where wear is heavy, they alone are not an adequate measure of tooth size. Attempts to gather information to test hypotheses of the kind proposed are rejected as "unlikely to produce significant new knowledge." Yet on the other hand, mountains of information continue to be collected on traits of unknown biological significance. Sometimes one suspects that if it requires precipitation or, better yet, electrophoresis, it is supported as "Science." When we see support being given to the collection of data principally because the technique is sophisticated while it is being denied where the rationale calls for techniques that are simple, then we feel that it might be appropriate to rephrase Harrison's complaint to express our own, to wit: "the methodology is modern, but the viewpoint so very old."

We suggest that the study of postPleistocene changes in the human dentition is a legitimate and important enterprise. At the moment, it is being pursued by altogether too few scholars. It is our hope that, if this paper has no other effect, at least it will have stimulated the collection of usable information which can be applied towards the solution of some of the issues raised.

\section{AKNOWLEDGMENTS}

The research on which this paper is based was accomplished despite refusals of support from the National Science Foundation and the National Institutes of Health.

For measurements on the Aztec population of San Juan Teotihuacan, we are greatly indebted to their excavator, Dr. Thomas H. Charlton, of the Department of Sociology and Anthropology at the University of Iowa. For the measurements on the Dickson Mound teeth, we are equally indebted to Dr. Milford $\mathrm{H}$. Wolpoff of the Department of Anthropology, Case Western Reserve University. We are grateful to Dr. Richard G. Wilkinson of the Department of Sociology and Anthropology at the State University of New York at Albany, and to Dr. Stephen Molnar of the Department of Anthropology at Washington University in St. Louis for their aid in bringing certain information to our attention. We thank Dr. James E. Harris and Dr. Melvyn J. Baer of the University of Michigan School of Dentistry for critical comments and advice as we wrestled with the revisions of this paper.

\section{LITERATURE CITED}

Auerbach, C. 1967 The chemical production of mutations. Science, 158: 1141-1147.

Bordes, Francois 1968 The old Stone Age. McGraw-Hill, New York.

Brabant, H., and F. Twiesselmann 1964 Observations sur l'évolution de la denture permanente humain en Europe occidentale. Bulletin du Groupement Internat. pour la Réch. scient. en Stomatologie, $7: 11-84$.

Brace, C. L. 1962 Cultural factors in the evolution of the human dentition. In: Culture and the Evolution of Man. M. F. Montagu, ed. Oxford University Press (Galaxy Book), New York. pp. 343-354.

1963 Structural reduction in evolution. Amer. Naturalist, 97: 39-49.

- 1964 The fate of the 'classic' Neanderthals: a consideration of hominid catastrophism. Current Anthropology, 5: 3.43.

1967a Environment, tooth form and size in the Pleistocene. J. Dent. Res., 46 (Supplement to No. 5): 809-816.

$1967 \mathrm{~b}$ The Stages of Human Evolution. Prentice-Hall, Inc., Englewood Cliffs, New Jersey.

Braidwood, R. J., and B. Howe 1962 Southwestern Asia beyond the lands of the Mediterranean littoral. In: Courses Toward Urban Life. R. J. Braidwood and G. R. Willey, eds. Aldine, Chicago. pp. 132-146.

Brues, A. M. 1966 "Probable Mutation Effect" and the evolution of hominid teeth and jaws. Am. J. Phys. Anthrop., 25: 169-170.

Dahlberg, A. A. 1960 The dentition of the first agriculturalists (Jarmo, Iraq). Am. J. Phys. Anthrop., 18: 243-256.

Deetz, J. 1969 The reality of the pilgrim fathers. Nat. Hist., $78 ; 32-45$.

Dockrell, R. B. 1956 Tooth size in Irish (Aran Island) families. Europ. Orthodont. Soc. Reports, 32: 200-216.

Garn, S. M. and A. B. Lewis 1958 Tooth size, body size, and 'giant' fossil man. Amer. Anthrop., 60: 874-880.

Goose, D. H. 1963 Dental measurement: an assessment of its value in anthropological 
studies. In: Dental Anthropology. D. R. Brothwell, ed. Pergamon Press, N.Y., pp. 125-148. Greene, D. L. 1970 Environmental influences on Pleistocene hominid dental evolution. Bioscience, 20: 276-279.

Greene, D. L., G. H. Ewing and G. J. Armelagos 1967 Dentition of a mesolithic population from Wadi Halfa, Sudan. Am. J. Phys. Anthrop., 27:41-56.

Harrison, G. A. 1965 Review of M. F. A. Mon tagu, ed. The Concept of Race. Race, 6: 288-297.

Henderson, J. G. 1882 Aboriginal remains near Naples, Ill. Smithson. Inst. Ann Rep., pp. 686.721.

Hole, F., K. V. Flannery and J. A. Neely 1969 Prehistory and Human Ecology of the Deh Luran Plain: An Early Village Sequence from Khuzistan, Iran. Mem. of the Mus. of Anthrop., Univ. of Mich., No. 1.

Holloway, R. L., Jr. 1966 Structural reduction through the "probable mutation effect": a critique with questions regarding human evolution. Am. J. Phys, Anthrop., 25: 7-11.

Hunt, E. E., Jr. 1960 The continuing evolution of modern man. Cold Spring Harbor Symp. on Quant. Biol., 24: 245-254.

Keith, A. 1920 Comment on L. H. D. Buxton, The teeth and jaws of savage man. Trans. Brit. Soc. for the Study of Orthodont., 19161920, pp. 85-86.

1923 The adaptational machinery concerned in the evolution of man's body. Nature (Supplement) No. 2807: pp. 257-268.

- 1924 Concerning certain structural changes which are taking place in our jaws and teeth. In: The Growth of the Jaws, Normal and Abnormal, in Health and Disease. The Dental Board of the United Kingdom, London, pp. 133-147.

- 1928 The Antiquity of Man. J. B. Lippincott, Philadelphia, Vol. II.

King, J. L., and T. H. Jukes 1969 Non-Darwinian evolution. Science, 164: 788-798.

Lunt, D. A. 1969 An Odontometric Study of Mediaeval Danes. Acta Odontolog. Scandinav. Supp. 55, 27, Glasgow.

Lysell, L. 1958a A biometric study of occlusion and dental arches in a series of Medieval skulls from N. Sweden. Acta Odontolog. Scandinav., 16: 177-203. 1958b An odontological examination of the remains of Erik XIV. Transac. Roy. Sch. Dentist., Stockholm. No. 1, pp. 1-16.

Matiegka, J. 1934 Homo Předmostensis: FosiIni Clovĕk $z$ Předmosti na Moravĕ. Publicat. Czech. Acad. Sci. and Art, Prague.

Montagne, P. 1961 Larousse Gastronomique: The Encyclopedia of Food, Wine and Cookery. C. Turgeon and N. Froud, eds. Crown Publishers, Inc., New York.

Patte, E. 1962 La Dentition des Néanderthaliens. Masson et Cie., Paris.

Post, R. H. 1962 Population differences in red and green color vision deficiency: a review, and a query on selection relaxation. Eugen. Quart., 9: $131-146$.

1965 Notes on relaxed selection in man. Anthrop. Anz., 29: 186-195.

1969a Deformed nasal septa and relaxed selection, II. Social Biol., 16: 179-196. $1969 \mathrm{~b}$ Tear duct size differences of age, sex and race. Am. J. Phys. Anthrop., 30: 85-88.

Rosenzweig, K. A. and Y. Zilberman 1967 Dental morphology of Jews from Yemen and Cochin. Am. J. Phys. Anthrop., 26: 15-22.

Sahly, A., H. Brabant and M. Bouyssou 1962 Observations sur les dents et les maxillaires du Mésolithique et de l'âge du fer trouvé dans la grotte de Rouffignac, département de la Dordogne, France. Bull. Group. Internat. Réch. scient. Stomatol., 5: 252-285.

Twiesselmann, F., and H. Brabant 1960 Récherches sur les dents et les maxillaires d'une population d'âge Franc de Coxyde. Bull. Group. Internat. Réch. scient. Stomatol., 3: 99-171; $355-400$.

Waterbolk, H. T. 1968 Food production in prehistoric Europe. Science, 162: 1093-1102.

Wendorf, F., R. Said and R. Schild 1970 Egyptian prehistory: some new concepts. Science, 169: 1161-1171.

Wolpoff, M. H. 1969 Metric Trends in Hominid Dental Evolution. Unpublished Doctoral Dissertation, Department of Anthropology, The University of Illinois.

1971 Metric Trends in Hominid Dental Evolution. Case Western Reserve University Studies in Anthropology, No. 2. Cleveland, in press.

Wright, S. 1964 Pleiotropy in the evolution of structural reduction and dominance. Amer. Naturalist, $98: 65-69$. 